\title{
Emergence of $\boldsymbol{J} A \boldsymbol{K} 2$-mutant primary myelofibrosis in myelodysplastic syndrome: rare case report, literature review, and implications for clonal progression
}

\author{
Michael J. Rauh • Jane Liesveld • W. Richard Burack • \\ John M. Bennett
}

Received: 2 September 2011 /Accepted: 20 September 2011 /Published online: 18 October 2011

(C) Springer-Verlag 2011

\section{Introduction}

Refractory anemia (RA) is a clonal myelodysplastic syndrome (MDS) characterized by dysplastic erythropoiesis and less than 5\% bone marrow (BM) blasts [1]. Although BM fibrosis can be seen in about $10-15 \%$ MDS patients and is a poor prognostic indicator, it is found more commonly in higher-risk cases and therefore only occasionally in RA [2-7]. Accordingly, recognizing that most cases of BM fibrosis occur in refractory anemia with excess (5-19\%) blasts (RAEB) MDS, the current World Health Organization (WHO) Classification includes the provisional entry, RAEB with fibrosis (RAEB-F). The working definition of RAEB-F includes diffuse coarse reticulin fibrosis, with or without collagen fibrosis. Since BM aspirates are often difficult to obtain from a fibrotic marrow, the presence of excess blasts is usually facilitated by BM biopsy immunohistochemistry (CD34 in particular). Moreover, increased numbers of dysplastic megakaryocytes may be seen [1].

\footnotetext{
M. J. Rauh

Department of Pathology and Molecular Medicine,

Richardson Laboratory, Queen's University,

88 Stuart Street,

Kingston, ON K7L 3N6, Canada

J. Liesveld · J. M. Bennett

Department of Medicine, University of Rochester Medical Center, Rochester, USA

W. R. Burack · J. M. Bennett $(\varangle)$

Department of Pathology, Hematopathology Section, the James P. Wilmot Cancer Center, University of Rochester Medical Center, 601 Elmwood Avenue,

Rochester, NY 14642, USA

e-mail: John_Bennett@URMC.Rochester.edu
}

Herein, we present a rare case of an RA patient whose $\mathrm{BM}$ picture evolved with fibrosis, yet sufficiently to satisfy WHO diagnostic criteria for the distinctive myeloproliferative neoplasm (MPN), primary myelofibrosis (PMF) [1]. Specifically, this evolution was characterized by the emergence of a $J A K 2$-mutant clone, splenomegaly, extramedullary hematopoiesis, and the loss of MDS-associated ring sideroblasts (RS) and a characteristic 20q chromosomal deletion. To the best of our knowledge, this is the first documented case report of $J A K 2^{V 617 F}$ PMF emerging from RA, providing insight into the process of clonal evolution.

\section{Case report}

A 64-year-old man presented for consultation, with a 3-year history of anemia. He had a remote history of smoking and a brother with MDS that transformed to acute myeloid leukemia (AML). Physical exam was remarkable for the absence of lymphadenopathy or hepatosplenomegaly. Complete blood counts revealed hematocrit 31.4\%, MCV $105 \mathrm{fl}$, WBC $3.3 \times 10^{9} / \mathrm{L}$, and platelets $118 \times 10^{9} / \mathrm{L}$.

Six months prior to consultation, peripheral blood and BM studies revealed non-specific dysplastic features that did not meet MDS thresholds. BM examination was repeated at consultation and was diagnostic for RA (Fig. 1). Specifically, the aspirate showed $>10 \%$ dysplastic erythroid forms (i.e., with irregular nuclear contours and megaloblastoid forms), a slightly decreased $\mathrm{M} / \mathrm{E}$ ratio (1.8:1), full granulocytic maturation with eosinophilia (9\%), and insufficient numbers of megakaryocytes for evaluation. Iron stores were decreased and there were $9 \%$ RS. The biopsy was mildly hypercellular $(50 \%)$, with areas of abnormally localized immature precursors and a few mononuclear megakaryocytes. Flow cytometry revealed $<1 \%$ blasts. Cytogenetics revealed 2 


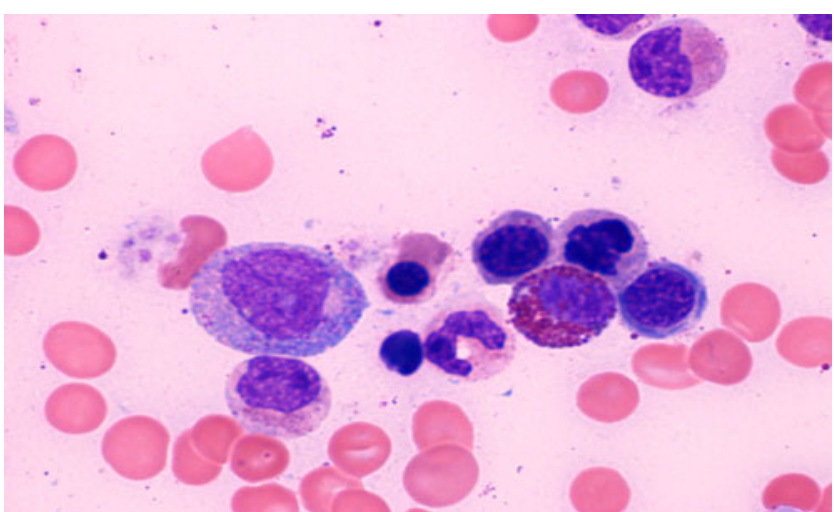

Fig. 1 Bone marrow aspirate morphology of refractory anemia stage. Note the megaloblastic erythroid precursors and absence of granulocytic dysplasia. Wright-Giemsa stain $\times 1,000$

normal metaphases and 19 with concurrent loss of the $\mathrm{Y}$ chromosome and deletion 20q13.1. Retrospective molecular testing was negative for $J A K 2^{V 617 F}$. No specific treatment was recommended.

The patient's counts remained fairly stable without interventions for almost 3 years. He then developed a respiratory illness, was found to have a hematocrit of $22 \%$, and received $2 \mathrm{U}$ of packed red cells. Repeat BM examination showed hypercellularity $(85 \%), \mathrm{M} / \mathrm{E}$ ratio of $1: 1$ with decreased myelopoiesis, increased megakaryocytes (small hypolobated and large polylobated forms) (Fig. 2a) with foci of clustering, and $2+$ reticulin fibrosis (Fig. 2b). Blasts were not increased. The karyotype remained unchanged (loss of $Y$ and $20 \mathrm{q}$ ), and $J A K 2$ status remained wild type. The differential diagnosis included progression of MDS to MDS with fibrosis or to an MDS/MPN overlapping disorder. Taken in the context of new pancytopenia (Hct 27\%, neutrophils $0.5 \times 10^{9} / \mathrm{L}$, Plts $63 \times 10^{9} / \mathrm{L}$ ), the patient was managed with growth factor support: erythropoietin (Epo) and granulocyte colony-stimulating factor.

Therapy was subsequently altered to include thalidomide and prednisone. Over the subsequent 2 years, the patient developed significant splenomegaly (up to $18 \mathrm{~cm}$ on ultrasonic examination) and progressive anemia. Repeat
$\mathrm{BM}$ examination indicated progression of the marrow fibrosis but no increase in immature cells. Specifically, cellularity was now 95\%, with increased and left-shifted erythropoiesis (with no RS seen), decreased myelopoiesis with normal maturation, increased and clustered megakaryocytes with atypia (large hyperlobated and small hypolobated forms). Reticulin deposition was increased (3+), and trichrome demonstrated slight collagen deposition. CD34 and CD117 immunostains revealed less than 5\% blasts. The $J A K 2^{V 617 F}$ mutation was detected. Potentially consistent with progression from an ancestral clone, the $20 \mathrm{q}$ deletion was no longer detectable by conventional cytogenetics. Instead, one metaphase was normal and 19/20 showed $45, \mathrm{X},-\mathrm{Y}$.

Three months following that BM examination, splenectomy revealed a 578-g specimen with extramedullary hematopoiesis, numerous megakaryocytes with "cloud-like" thickly connected nuclear lobes (Fig. 3a), marked $(3+)$ reticulin fibrosis (Fig. 3b), and no excess blasts $(<1 \%)$, consistent with the concurrent $J A K 2$ mutation-positive myelofibrosis BM diagnosis. Postoperative course was complicated by multi-organ failure, sepsis, Clostridium difficile colitis, aspiration pneumonia/respiratory failure with anoxic brain injury, requiring prolonged hospitalizations and transfers to and from a skilled nursing facility.

Repeat BM studies 5 months later revealed hypercellularity, with interval loss of megakaryocyte hyperplasia, and increased blasts ( $7 \%$ in the aspirate). The karyotype revealed 3 normal metaphases and 17/20 with loss of Y. However, JAK2 $2^{V 617 F}$ was no longer detectable. No additional treatment was provided except for supportive care. The patient expired approximately 6 years after the original diagnosis.

\section{Discussion}

BM fibrosis has long been associated with MDS [2-5]. More recent studies have clarified that significant fibrosis (grades 2-3) which occurs in $10-15 \%$ of MDS patients, is
Fig. 2 Bone marrow aspirate morphology of transition to primary myelofibrosis. a clusters of bizarre megakaryocytes with balloon-shaped nuclei. H\&E $\times 400$. b $2+$ myelofibrosis. Reticulin stain $\times 400$
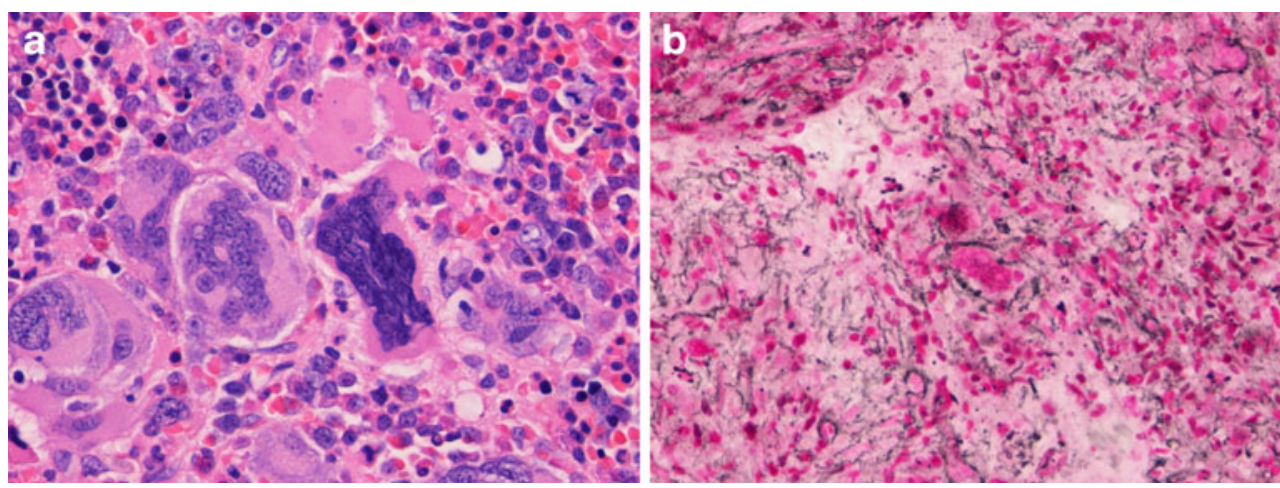
Fig. 3 Splenectomy pathology at primary myelofibrosis stage. a spleen: extramedullary hematopoiesis with megakaryocyte. H\&E $\times 400$. b. spleen: $3+$ myelofibrosis. Reticulin stain $\times 400$

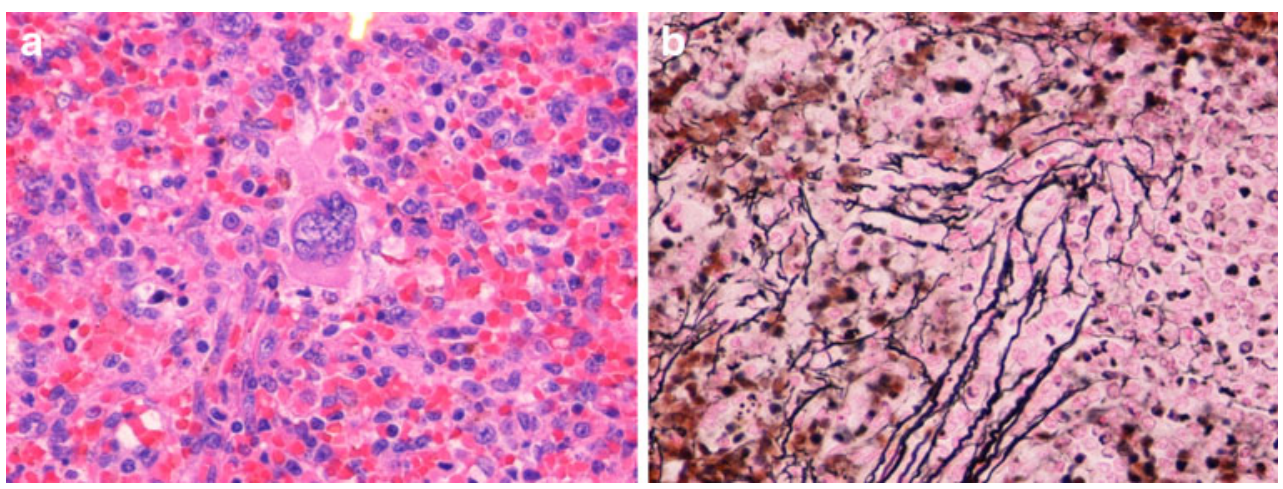

associated with advanced disease and poor prognosis $[6,7]$. However, in our case, the appearance of fibrosis coincided with the loss of MDS-associated RS and del(20q). Furthermore, there have been descriptions of MDS patients transitioning to acute panmyelosis with myelofibrosis (APMF) [8-10]. However, APMF is characterized by an abrupt onset with fever and bone pain, with no to minimal splenomegaly, more numerous megakaryocytes and leuke- mic level $(\geq 20 \%)$ blasts [1]. These features were lacking in our case.

A further differential consideration is whether the initial dysplasia was simply part of the PMF clone. Although some degree of dysplasia (particularly megakaryocytic) can be seen in PMF, dysplasia is not to the extent of MDS and may require subtle flow cytometric analysis to discern [1, 11, 12]. Again, the transition to PMF in this case was

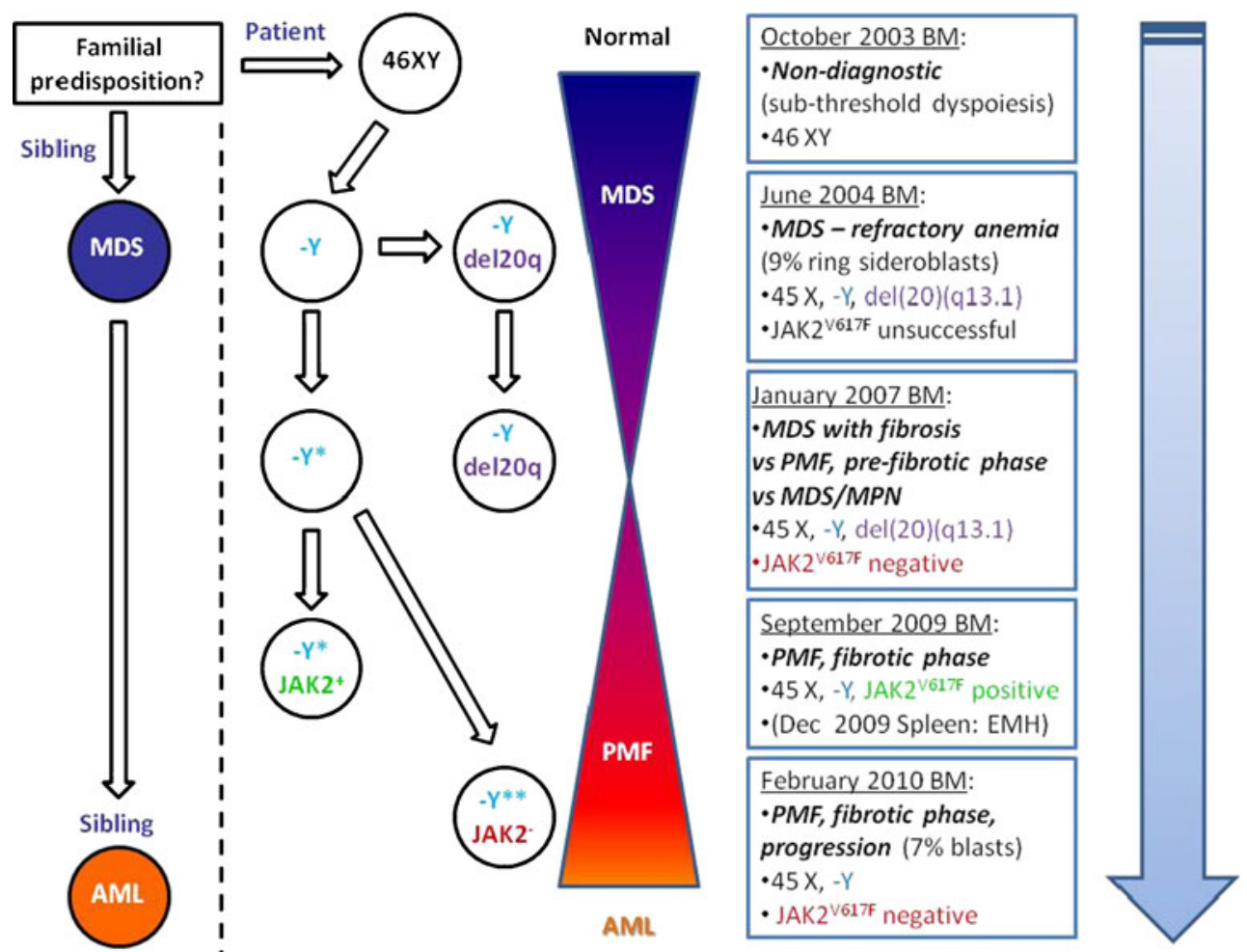

Fig. 4 Case report summary. The left side of the dashed line represents the clinical course of the sibling of the index case (patient), and raises the unproven possibility of familial predisposition to myeloid malignancies and/or common environmental influences. To the right of the dashed line is depicted the clinical course of the index case. Furthest to the right are listed the chronological order of respective bone marrow (and splenic) pathological diagnoses, with cytogenetic and molecular findings. The middle of the right panel depicts the differential emergence of MDS (blue) and PMF (red) diagnoses, on a spectrum from normal to AML. To the left of this, is a depiction of the postulated phylogenic relationships of the different clones (including their cytogenetic/molecular signatures). (MDS myelodysplastic syndrome, $M P N$ myeloproliferative neoplasm, $P M F$ primary myelofibrosis, $A M L$ acute myeloid leukemia, $E M H$ extramedullary hematopoiesis, $-Y$ deletion of entire $Y$ chromosome, $-Y^{*}$ and $-Y^{* *}$ postulated additional mutations present, del deletion, JAK2+ Janus kinase 2 mutation $(J A K 2)$ is present, $J A K 2$ - wild-type at this locus and/or mutation was not found) 
associated with the loss of two clearly MDS-associated features: RS and del(20q).

Another differential diagnostic consideration included an unclassifiable (U), overlapping disorder: MDS/MPN-U. In particular, given the previous documentation of $9 \%$ RS and the emergence of $J A K 2^{\mathrm{V} 617 \mathrm{~F}}$, the provisional MDS/MPN-U entity RA with RS associated with marked thrombocytosis (RARS-T) was considered [1]. However, our patient never had a thrombocytosis (platelet count $\geq 450 \times 10^{9} / \mathrm{L}$ ), RS were less than the required $15 \%$ threshold, and RS were no longer detectable upon the myelofibrotic transition.

Thus, we propose this case represented a true example of PMF emerging from RA. Accordingly, there have been a few similar reports of "transitional" [13] MDS $\rightarrow$ PMF [10, 13-17], although ours may be the first documented in the $J A K 2$ molecular era. A model is presented in Fig. 4, depicting the transition to $J A K 2^{V 617 F}$-mutant PMF from antecedent $J A K 2^{w t}$ RA. Consistent with the existence of at least two serially distinct but related clones, both disorders were characterized by loss of the Y chromosome, yet RA was marked by $9 \%$ RS and del(20q), and PMF showed neither. Arguing for a third clonogenic intermediary, blastic progression of PMF ultimately resulted with loss of $J A K 2^{V 617 F}$ allele, as has been reported during the transformation of $B C R-A B L 1$-negative MPNs [18, 19].

A final curious component to this case (leftmost aspect of Fig. 4), is that the sibling of our patient also acquired MDS that transformed to AML. Familial occurrence of MDS and/ or AML is rare, tends to occur at younger presentation, and in families with more than one affected first-degree relative. It is associated with BM failure syndromes, in families with familial monosomy 7 [20], inherited telomere abnormalities [21], mutations of CEBPA [22, 23], or in familial platelet disorder with propensity to develop myeloid malignancy (FPD/AML) in which germline RUNXI mutations have been implicated [22, 24-26]. Moreover, although not yet associated with familial MDS/AML, mutations in TET2 and ASXL1 are common in MDS/MPN [27, 28], and germline TET2 variants have been described in myeloid malignancy [29]. Whether the similar disorders in these siblings arose due to common predisposing genetic and/or environmental factors remains to be determined.

\footnotetext{
Acknowledgments We wish to thank Phoebe Downing for excellent administrative and clerical assistance. MJR and JMB conceived and wrote the manuscript, with editorial contributions from WRB and JL. Clinical data was provided by JL. Pathological diagnoses and information were provided by JMB and WRB. The authors also acknowledge the diagnostic contributions of Dr. Raymond Felgar, Dr. Arnaldo Arbini, Dr. Joseph Weisensel, and Dr. Michael Petzar, formerly of the Department of Pathology, Hematopathology Section, University of Rochester Medical Center. Moreover, the authors wish to acknowledge the clinical care provided to our patient by Dr. Ayalew Tefferi and colleagues at the Mayo Clinic. Finally, MJR wishes to thank JMB and colleagues for hosting his Hematopathology Elective
}

in May 2010, while a resident at the University of Toronto. No funding was provided for this submission. The authors have no relevant conflicts of interest to declare.

\section{References}

1. Swerdlow SH, Campo E, Harris NL, Jaffe ES, Pileri SA, Stein H, Thiele J, Vardiman JW (eds) (2008) WHO Classification of Tumours of Haematopoietic and Lymphoid Tissues, 4th Edition. Lyon: International Agency for Research on Cancer (IARC)

2. Sultan C, Sigaux F, Imbert M, Reyes F (1981) Acute myelodysplasia with myelofibrosis: a report of eight cases. Br J Haematol 49(1):11-16

3. Lambertenghi-Deliliers G, Orazi A, Luksch R, Annaloro C, Soligo D (1991) Myelodysplastic syndrome with increased marrow fibrosis: a distinct clinico-pathological entity. Br J Haematol 78(2):161-166

4. Maschek H, Georgii A, Kaloutsi V, Werner M, Bandecar K, Kressel MG, Choritz H, Freund M, Hufnagl D (1992) Myelofibrosis in primary myelodysplastic syndromes: a retrospective study of 352 patients. Eur J Haematol 48(4):208-214

5. Bain BJ (1999) The relationship between the myelodysplastic syndromes and the myeloproliferative disorders. Leuk Lymphoma 34(5-6):443-449

6. Buesche G, Teoman H, Wilczak W, Ganser A, Hecker H, Wilkens L, Göhring G, Schlegelberger B, Bock O, Georgii A, Kreipe H (2008) Marrow fibrosis predicts early fatal marrow failure in patients with myelodysplastic syndromes. Leukemia 22(2):313-322

7. Della Porta MG, Malcovati L, Boveri E, Travaglino E, Pietra D, Pascutto C, Passamonti F, Invernizzi R, Castello A, Magrini U, Lazzarino M, Cazzola M (2009) Clinical relevance of bone marrow fibrosis and CD34-positive cell clusters in primary myelodysplastic syndromes. J Clin Oncol 27(5):754-762

8. Yeung K, Trowbridge AA (1977) Idiopathic acquired sideroblastic anemia terminating in acute myelofibrosis: case report and review of leterature. Cancer 39(1):359-365

9. Butler WM, Taylor HG, Viswanathan U (1982) Idiopathic acquired sideroblastic anemia terminating in acute myelosclerosis. Cancer 49(12):2497-2499

10. Kamei S, Shinohara K, Oeda E (1993) Myelodysplastic syndrome associated with myelofibrosis, a report of 3 cases. Intern Med 32 (8):668-671

11. Bain BJ (2010) Megakaryocyte dysplasia in primary myelofibrosis. Am J Hematol 85(11):886

12. Feng B, Verstovsek S, Jorgensen JL, Lin P (2010) Aberrant myeloid maturation identified by flow cytometry in primary myelofibrosis. Am J Clin Pathol 133(2):314-320

13. Reilly JT, Dolan G (1991) Proposed classification for the myelodysplasia/myelofibrosis syndromes. Br J Haematol 79(4):653

14. Lukowicz DF, Myers TJ, Grasso JA, Albala MM (1982) Sideroblastic anemia terminating in myelofibrosis. Am J Hematol 13 (3):253-257

15. Mufti GJ, Hamblin TJ, Seabright M (1982) Acute transformation of a myeloproliferative state in sideroblastic anaemia with abnormal karyotype. J Med Genet 19(6):478

16. Verhoef GE, DeWolf-Peeters C, Ferrant A, Boogaerts MA (1990) A case of myelodysplastic syndrome and myelofibrosis. Br $\mathrm{J}$ Haematol 74(3):373-375

17. Verhoef GE, De Wolf-Peeters C, Ferrant A, Deprez S, Meeus P, Stul M, Zacheé P, Cassiman JJ, Van den Berghe H, Boogaerts MA (1991) Myelodysplastic syndromes with bone marrow fibrosis: a myelodysplastic disorder with proliferative features. Ann Hematol 63(5):235-241

18. Campbell PJ, Baxter EJ, Beer PA, Scott LM, Bench AJ, Huntly BJ, Erber WN, Kusec R, Larsen TS, Giraudier S, Le Bousse- 
Kerdilès MC, Griesshammer M, Reilly JT, Cheung BY, Harrison CN, Green AR (2006) Mutation of JAK2 in the myeloproliferative disorders: timing, clonality studies, cytogenetic associations, and role in leukemic transformation. Blood 108(10):3548-3555

19. Theocharides A, Boissinot M, Girodon F, Garand R, Teo SS, Lippert E, Talmant P, Tichelli A, Hermouet S, Skoda RC (2007) Leukemic blasts in transformed JAK2-V617F-positive myeloproliferative disorders are frequently negative for the JAK2-V617F mutation. Blood 110(1):375-379

20. Owen C, Barnett M, Fitzgibbon J (2008) Familial myelodysplasia and acute myeloid leukaemia-a review. Br J Haematol 140(2):123-132

21. Kirwan M, Vulliamy T, Marrone A, Walne AJ, Beswick R, Hillmen P, Kelly R, Stewart A, Bowen D, Schonland SO, Whittle AM, McVerry A, Gilleece M, Dokal I (2009) Defining the pathogenic role of telomerase mutations in myelodysplastic syndrome and acute myeloid leukemia. Hum Mutat 30(11):1567-1573

22. Owen CJ, Toze CL, Koochin A, Forrest DL, Smith CA, Stevens JM, Jackson SC, Poon MC, Sinclair GD, Leber B, Johnson PR, Macheta A, Yin JA, Barnett MJ, Lister TA, Fitzgibbon J (2008) Five new pedigrees with inherited RUNX1 mutations causing familial platelet disorder with propensity to myeloid malignancy. Blood 112(12):4639-4645

23. Smith ML, Cavenagh JD, Lister TA, Fitzgibbon J (2004) Mutation of CEBPA in familial acute myeloid leukemia. N Engl J Med 351 (23):2403-2407
24. Ripperger T, Steinemann D, Göhring G, Finke J, Niemeyer CM, Strahm B, Schlegelberger B (2009) A novel pedigree with heterozygous germline RUNX1 mutation causing familial MDSrelated AML: can these families serve as a multistep model for leukemic transformation? Leukemia 23(7):1364-1366

25. Langabeer SE, Owen CJ, McCarron SL, Fitzgibbon J, Smith OP, O'Marcaigh A, Browne P (2010) A novel RUNX1 mutation in a kindred with familial platelet disorder with propensity to acute myeloid leukaemia: male predominance of affected individuals. Eur J Haematol 85(6):552-553

26. Owen C (2010) Insights into familial platelet disorder with propensity to myeloid malignancy (FPD/AML). Leuk Res 34 (2):141-142

27. Flach J, Dicker F, Schnittger S, Kohlmann A, Haferlach T, Haferlach C (2010) Mutations of JAK2 and TET2, but not CBL are detectable in a high portion of patients with refractory anemia with ring sideroblasts and thrombocytosis. Haematologica 95(3):518-519

28. Szpurka H, Jankowska AM, Makishima H, Bodo J, Bejanyan N, Hsi ED, Sekeres MA, Maciejewski JP (2010) Spectrum of mutations in RARS-T patients includes TET2 and ASXL1 mutations. Leuk Res 34(8):969-973

29. Schaub FX, Looser R, Li S, Hao-Shen H, Lehmann T, Tichelli A, Skoda RC (2010) Clonal analysis of TET2 and JAK2 mutations suggests that TET2 can be a late event in the progression of myeloproliferative neoplasms. Blood 115(10):2003-2007 